\title{
FORMULATION DEVELOPMENT AND CHARACTERIZATION OF GASTRORETENTIVE DRUG DELIVERY SYSTEMS OF LORATADINE
}

\author{
SRINU NAIK SAPAVATUa, RAJENDRA KUMAR JADI ${ }^{\mathrm{b}^{*}}$
}

aDepartment of Chemical Engineering, University College of Technology, Osmania University, Hyderabad 500007, Telangana State, India, bDepartment of Pharmacy, University College of Technology, Osmania University, Hyderabad 500007, Telangana State, India Email: rajendra.rajaji@gmail.com

Received: 02 Aug 2019, Revised and Accepted: 23 Sep 2019

\section{ABSTRACT}

Objective: The main objective of the research work is to develop a single unit non-effervescent drug delivery system of Loratadine (LTD) by direct compression process to prolong the gastric residence time (GRT).

Methods: LTD non-effervescent floating tablets were prepared with different polymers like hydroxypropyl methylcellulose (HPMC) K15M, HPMC K100M (i.e.: 1:1, 1:2, 1:3) as release retardants. Glyceryl behenate (Compritol 888 ATO) and Glyceryl palmitostearate (Precirol AT0 5) were used $(1: 1,1: 2,1: 3)$ as low-density lipids to impart buoyancy for longer period.

Results: The drug (LTD) and excipient (i.e. HPMC, low-density lipid aids, etc.)) interaction studies were carried out by Fourier Transform Infrared Spectroscopy (FTIR) and there was no likely interaction involving them. The developed LTD floating matrix tablets were characterized by pre and post-compression parameters and all results were found within the pharmacopoeial limits. The cumulative percentage of drug release ranges from $56.87 \pm 0.25 \%$ (F12) to $99.87 \pm 0.09 \%$ (F2). The drug release profiles of the all formulations (F1 to F12) were subjected to various pharmacokinetic parameters and the optimized formulation (F3) followed the Korsmeyer Peppas $\left(\mathrm{R}^{2}=0.996\right)$ model with non-Fickian diffusion ( $\left.\mathrm{n}>0.5\right)$. The obtained data by radiographic images of F3 formulation showed the GRT of $6 \pm 0.5 \mathrm{~h}(\mathrm{n}=3)$.

Conclusion: Hence, from all evaluation studies, it was evident that F3 formulation was optimized ( $99.82 \pm 1.63 \%$ drug release in $12 \mathrm{~h}$ ).

Keywords: Buoyant, Non-effervescent, Low-density lipids, Direct compression

(C) 2019 The Authors. Published by Innovare Academic Sciences Pvt Ltd. This is an open-access article under the CC BY license (http://creativecommons.org/licenses/by/4.0/) DOI: http://dx.doi.org/10.22159/ijap.2019v11i6.35194

\section{INTRODUCTION}

Oral directions of drug administration have broad recognition of up to $50-60 \%$ of whole dosage forms [1]. Oral drug delivery (i.e.: tablets, capsule, powders, emulsions, suspensions, etc.)) is considered as the most common, most popular, convenient and safe (when compared to parental route) [2]. Solid dosage forms are more popular because of ease of administration, accurate dosage, selfmedication, pain avoidance and most importantly the patient compliance [3-5]. The majority accepted solid dosage forms are tablets and capsules; one of the important drawbacks of solid dosage forms; especially solids are not recommended to pediatrics, geriatrics and unconscious patients [6-8]. Gastrointestinal physiology offers additional flexibility in dosage form design than the popularity of other routes $[9,10]$.

The term extended-release (i.e. controlled release, sustained release, etc,) formulations are used to categorize drug delivery systems (DDS) that are considered to accomplish or extend phase of time subsequent for administration of a single dose and as an alternative to multiple dosage, having a benefit that the drug release was longstanding and it has been noticeable to pharmaceutical manufacturing [11-15]. LTD is a lipophilic, non-sedating $\mathrm{H}_{1}$ blocker and used to treat seasonal allergic rhinitis having low bioavailability (40\%), and biological half-life ( $8 \mathrm{~h}$ ). So, patients can avoid frequent administrations in a day [16-20]. Such frequent drug administration may reduce patient obedience and therapeutic effectiveness [21-25]. To overcome the above-mentioned problems it is required to convey the single dose for an extended period. Besides, LTD shows the greatest solubility at acidic $\mathrm{pH}$ and it is an appropriate candidate for the expansion of gastroretentive drug delivery systems (GRDDS). The aim of extended release (ER) DDS is to be customized in such a method with the intention; extra residence time in the stomach to release the drug before the absorption window. The goal of GRDDS is to provide a beneficial quantity of the drug to the appropriate location in the body and sustain the required drug concentration. To avoid the problems associated with the delivery of LTD, we planned to formulate LTD in an extended-release floating matrix formulation. This will allow us to reduce the frequency of administration and enhances patient compliance. To achieve the goal we have used lowdensity lipids or floating aids like compritol and precirol that can allow the formulation to stay on top of the gastric contents. It will avoid the first-pass metabolism and will improve the bio-availability of the formulation.

\section{MATERIALS AND METHODS}

\section{Materials}

Loratadine received as a gift sample from Hetero Labs Ltd, Hyderabad, India. HPMC K15 M and HPMC K100 M procured from B and $\mathrm{K}$ Technologies, China. Compritol and precirol were purchased from Gattefosse, Germany. MCC-(Avicel PH 200), Aerosil and Magnesium stearate from SD Fine Chemicals Ltd., Mumbai. Hydrochloric acid from Merck specialities Pvt. Ltd. Mumbai, India

\section{Methods}

Pre-compression characterization

Drug excipient compatibility studies

\section{Fourier transform infrared spectroscopy (FTIR)}

The drug excipient compatibility study was carried out by FTIR with in the frequency range of $4000-400 \mathrm{~cm}^{-1}$ and $4 \mathrm{~cm}^{-1}$ resolution. The IR spectra for the test samples were obtained using the $\mathrm{KBr}$ disk method using an FTIR (Star Tech Labs Pvt. Ltd., Hyderabad) [26].

\section{Differential scanning calorimetry (DSC)}

The differential thermal analyzer was used to find out the presence of any interaction among drug and excipients. About 5-15 mg of the sample was taken in pierced DSC aluminium pan and scanned in the temperature range of $50-300{ }^{\circ} \mathrm{C}$ and the heating rate was 10 ${ }^{\circ} \mathrm{C} / \mathrm{min}$.; nitrogen served as purged gas and the system was cooled down by liquid nitrogen [27]. 


\section{Flow properties of the powder blend}

The powder mixtures of different formulations were evaluated for angle of repose $(\Theta)$, bulk density $\left(\mathrm{gm} / \mathrm{cm}^{3}\right)$, tapped density $\left(\mathrm{gm} / \mathrm{cm}^{3}\right)$, Carr's index or compressibility index (\%) and Hausner's ratio. [28] And the evaluation test results are shown in table 2.

\section{Angle of repose ( $\theta)$}

The fixed funnel method was employed to measure the ' $\theta$ ' and it was determined by below formula

\section{$\theta=\operatorname{Tan}^{-1}(\mathbf{h} / \mathbf{r})$}

Here ' $\theta$ ' is the angle of repose, ' $h$ ' is the height of the pile and ' $r$ ' is the radius of the base.

\section{Carr's index or compressibility index (\%)}

Bulk density (BD) and tapped densities (TD) were determined by the following formulas.

$$
\begin{gathered}
\text { WD }=\begin{array}{c}
\text { Weight of the sample } \\
\text { Volume of the sample } \\
\text { Weight of the sample }
\end{array} \\
\text { Tapped volume of the sample }
\end{gathered}
$$

The carr's index was calculated by the following formula

$$
\text { Carr's index }=- \text { TD }- \text { BD } \times 100
$$

\section{Hausner's ratio}

Hausner's ratio was calculated by the following formula

$$
\text { Hausner's ratio }=- \text { TD }-
$$

\section{Construction of loratadine calibration curve}

The study started with the construction of a standard calibration curve of Loratadine. The standard graph of LTD with $0.1 \mathrm{~N}$ hydrochloric acid $(\mathrm{HCl})$ was plotted by taking concentration ranging from $5 \mu \mathrm{g} / \mathrm{ml}$ to $45 \mu \mathrm{g} / \mathrm{ml}$ on X-axis and absorbance values on Y-axis [29-30].

\section{Preparation of LTD non-effervescent floating matrix tablets}

Floating tablets containing LTD were prepared by a direct compression technique [31]. Polymers and floating aids ratios were taken as $1: 1,1: 2$, and 1:3 (table 1). LTD and all other additives are precisely weighed and sieved through 44 mesh.

The LTD was well mixed with a magnitude of necessary polymers (HPMC K15M, HPMC K100M), floating aids (Compritol 888 ATO and Precirol ATO 5), MCC (Avicel PH 200) in geometric proportions. After that the blend was lubricated with previously weighed, sieved magnesium stearate and aerosil. Finally, about $100 \mathrm{mg}$ of the

\begin{tabular}{|c|c|c|c|c|c|c|c|c|c|c|c|c|}
\hline *Formulation (mg/tablet) & F1 & F2 & F3 & F4 & F5 & F6 & F7 & F8 & F9 & F10 & F11 & F12 \\
\hline Drug (LTD) & 10 & 10 & 10 & 10 & 10 & 10 & 10 & 10 & 10 & 10 & 10 & 10 \\
\hline HPMC K15M & 10 & 20 & 30 & - & - & - & 10 & 20 & 30 & - & - & - \\
\hline HPMC K100M & - & - & - & 10 & 20 & 30 & - & - & - & 10 & 20 & 30 \\
\hline Compritol 888 ATO & 10 & 20 & 30 & - & - & - & 5 & 10 & 15 & 5 & 10 & 15 \\
\hline Precirol ATO 5 & - & - & - & 10 & 20 & 30 & 5 & 10 & 15 & 5 & 10 & 15 \\
\hline Avicel PH 200 & 65 & 45 & 25 & 65 & 45 & 25 & 65 & 45 & 25 & 65 & 45 & 25 \\
\hline Talc & 2 & 2 & 2 & 2 & 2 & 2 & 2 & 2 & 2 & 2 & 2 & 2 \\
\hline Aerosil & 2 & 2 & 2 & 2 & 2 & 2 & 2 & 2 & 2 & 2 & 2 & 2 \\
\hline Magnesium stearate & 1 & 1 & 1 & 1 & 1 & 1 & 1 & 1 & 1 & 1 & 1 & 1 \\
\hline Total weight & 100 & 100 & 100 & 100 & 100 & 100 & 100 & 100 & 100 & 100 & 100 & 100 \\
\hline
\end{tabular}
lubricated blend was subjected to compression by using a $6 \mathrm{~mm}$ circular standard flat-faced punch on 10 stations rotary tablet punching machine (i.e. Karnavathi, Gujarat, India) [32].

Table 1: Composition of LTD floating matrix tablets

${ }^{*}$ Each value represents mean $\pm S D(n=30)$

\section{Post-compression characterization}

The above-compressed LTD floating tablets should be characterized by several specifications, which include weight variation, thickness, friability; hardness and drug content uniformity, etc., were shown in table 3.

\section{Weight variation (mg)}

The weight of the prepared LTD floating tablets (i.e. $n=20$; randomly from every batch, then average weight should be well-thought-out) determined by using an electronic balance (Shimadzu, AUX220, Japan) [33]

\section{Thickness (mm)}

The thickness of the prepared LTD floating tablets (i.e. $n=20$ ) measured by, vernier calipers, tablet thickness is reliable from batch to batch or within a batch only if the tablet granulation or dust mix is satisfactorily dependable on particle size and size distribution, if the punch tooling is of regular length, and the tablet press is clean and in good working order. Thickness must be controlled for consumer acceptance of the product, and to facilitate packaging [34].

\section{Friability (\%)}

The friability test was performed with prepared LTD floating tablets (i.e. $n=20$; unintentionally from the entire batches) by placing in Roche friabilator and allowed to make 100 revolutions (i.e. $25 \mathrm{rpm}$ for $4 \mathrm{~min})$.

$$
\% \text { Friability }=\frac{W_{1}-W_{2}}{W_{1}} \times 100
$$

Where $\mathrm{W}_{1}$ is the initial weight of tablets; $\mathrm{W}_{2}$ is the final weight of dedusted tablets; and the values $<1 \%$ is usually good [35].

\section{Hardness $\left(\mathrm{Kg} / \mathrm{cm}^{2}\right)$}

The hardness (i.e. $n=6$; erratically from every grouping after that middling should be deliberate) of the prepared LTD floating tablets were measured by using Pfizer type hardness tester (Dolphin Pharmacy Instruments, Pvt. Ltd., Mumbai). By this test, the tablet mechanical potency or crushing strength will be determined and the average hardness with standard deviation was reported [36].

\section{Content uniformity (\%)}

The prepared LTD floating tablets $(n=6)$ were collected at random and pulverized. Several fine particles corresponding to the weight of 1 tablet was transferred into $100 \mathrm{ml}$ volumetric flask (VF), to this $100 \mathrm{ml}$ of methanol was added, then the solution was subjected to sonication for about $2 \mathrm{~h}$. The solution was up to the mark with an equivalent concentration of the standard solution (i.e. $0.1 \mathrm{~N} \mathrm{HCl}$ ) [37].

\section{In vitro buoyancy studies (h)}

The in vitro floating $(\mathrm{n}=3)$ was determined by the reported method. Here, the prepared LTD was placed in a $100 \mathrm{ml}$ beaker containing $0.1 \mathrm{~N} \mathrm{HCl}$. The time required to float the tablet or rise from the bottom of the beaker to the surface of the liqid called floating lag 
time (FLT) and the total duration of tablet float on the surface is called as total floating time (TFT) [38].

\section{In vitro dissolution (\%)}

The drug release or in vitro dissolution studies (i.e. $n=6$ ) of LTD noneffervescent floating tablets were carried out with USP dissolution type-II (i.e. paddle) method at $50 \mathrm{rpm}$ in $900 \mathrm{ml}$ of $0.1 \mathrm{~N} \mathrm{HCl}$ as dissolution medium, maintained at $37^{\circ} \mathrm{C} \pm 0.5^{\circ} \mathrm{C}$. About to $5 \mathrm{ml}$ of aliquot (i.e. sample) was withdrawn at predetermined time intervals for every 1 hour up to $12 \mathrm{~h}$ and replaced with $5 \mathrm{ml}$ of fresh medium (i.e. $0.1 \mathrm{~N} \mathrm{HCl}$ ) each time. The samples were analyzed by using a double beam UV visible spectrophotometer (Elico, SL210, Hyderabad) at $280 \mathrm{~nm}$. By using a standard calibration curve, calculate the cumulative percentage of drug release [39-40].

\section{In vivo buoyancy studies (h)}

In vivo gastric retention time (GRT) was determined by X-ray procedure in healthy human volunteers $(n=3)$. The procedure of the radiographic studies was approved by the institutional human ethical committee (IHEC). For in vivo study (i.e.: Proposal no. IRBAGI/2018-19/11), Barium sulphate $\left(\mathrm{BaSO}_{4}\right)$ containing LTD floating tablets were prepared by a similar method as described in the formulation. In this revision, part of the LTD was replaced using $\mathrm{BaSO}_{4}$ each one of the ingredients remained equivalent [41].

\section{Mechanism of drug release kinetics}

The drug release data of LTD prepared floating matrix tablets were fitted into different kinetic models representing Zero order, First order, Higuchi and Peppas model to know the release mechanism [42-45].

\section{RESULTS AND DISCUSSION}

\section{Construction of loratadine calibration curve}

The maximum concentration $\left(\lambda_{\max }\right)$ of LTD in $0.1 \mathrm{~N} \mathrm{HCl}$ was scanned and found to have the maximum absorbance at $280 \mathrm{~nm}$. The standard graph of LTD in $0.1 \mathrm{~N} \mathrm{HCl}$ was shown in fig. 1 by taking concentration ranging from $5 \mu \mathrm{g} / \mathrm{ml}$ to $45 \mu \mathrm{g} / \mathrm{ml}$ and a good correlation was obtained with a regression coefficient $\left(\mathrm{R}^{2}\right)$ value of 0.998 .

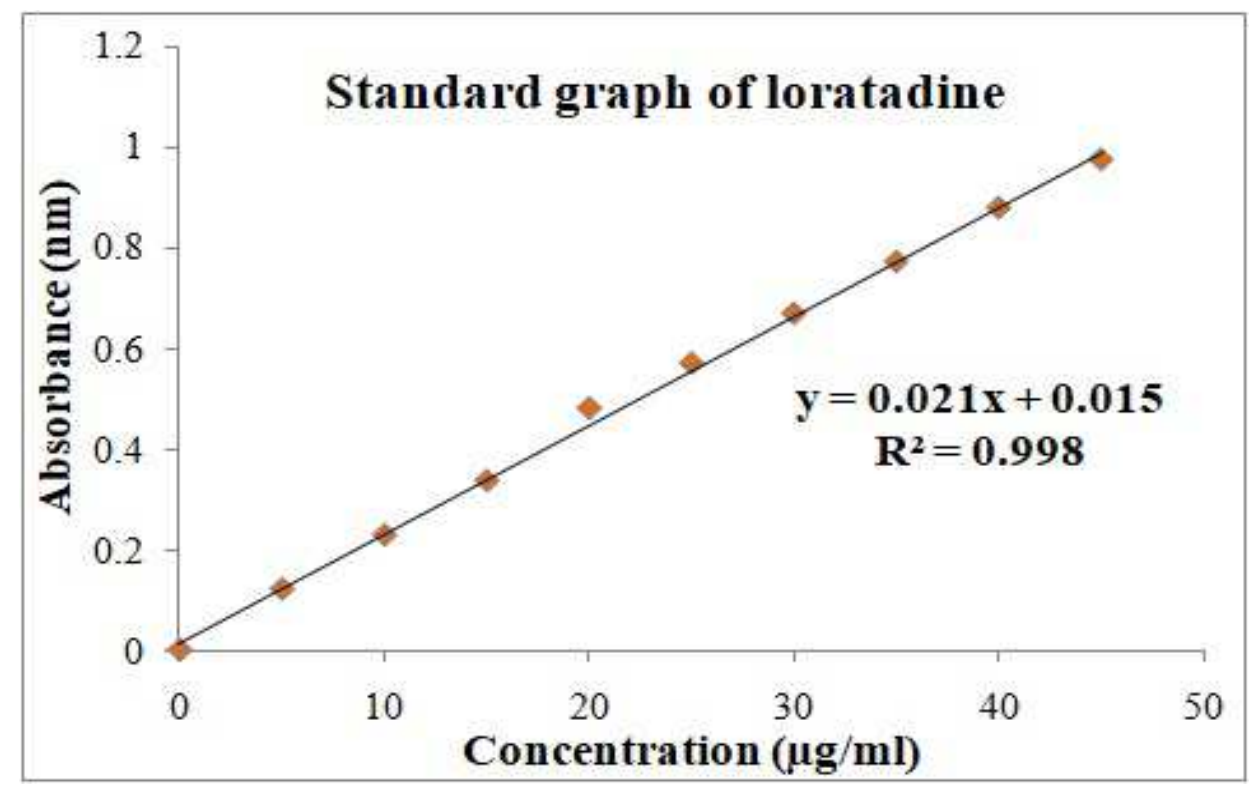

Fig. 1: Standard graph of LTD; $(n=1)$

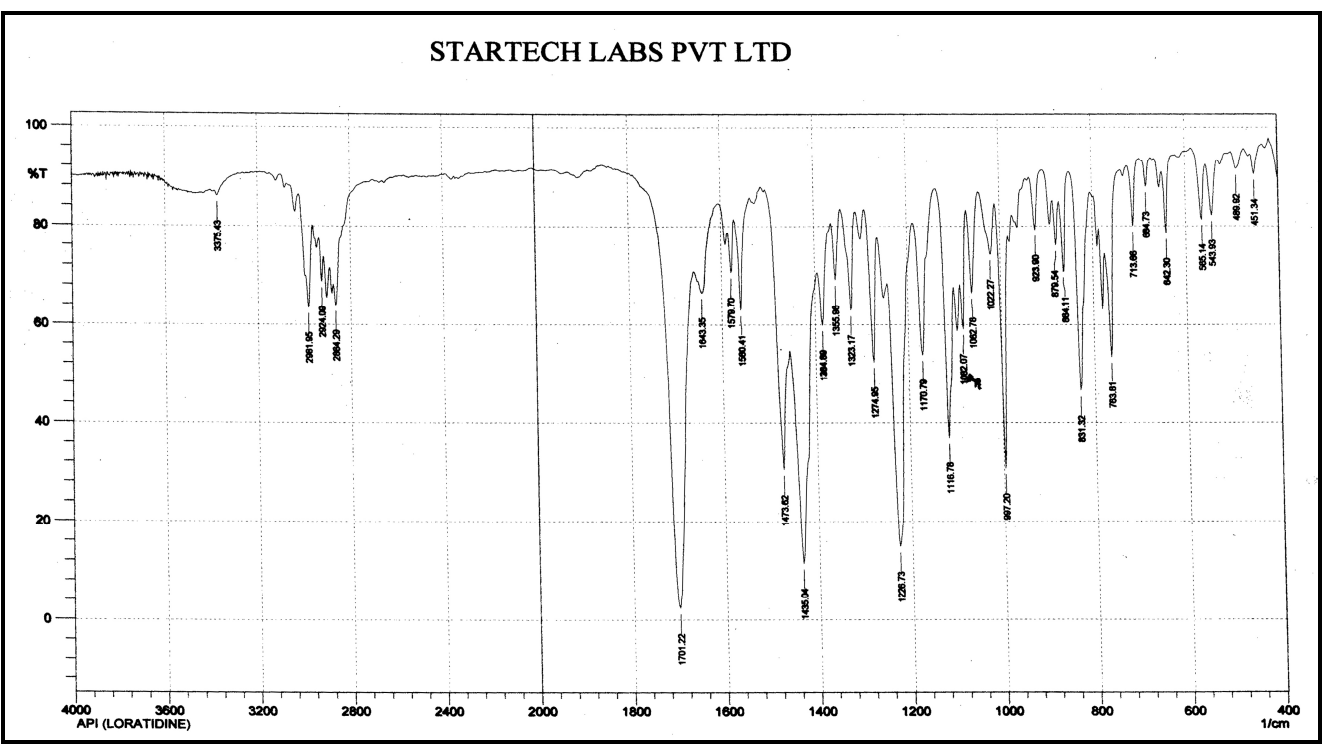

Fig. 2: FTIR spectrum of the pure drug; $(n=1)$ 


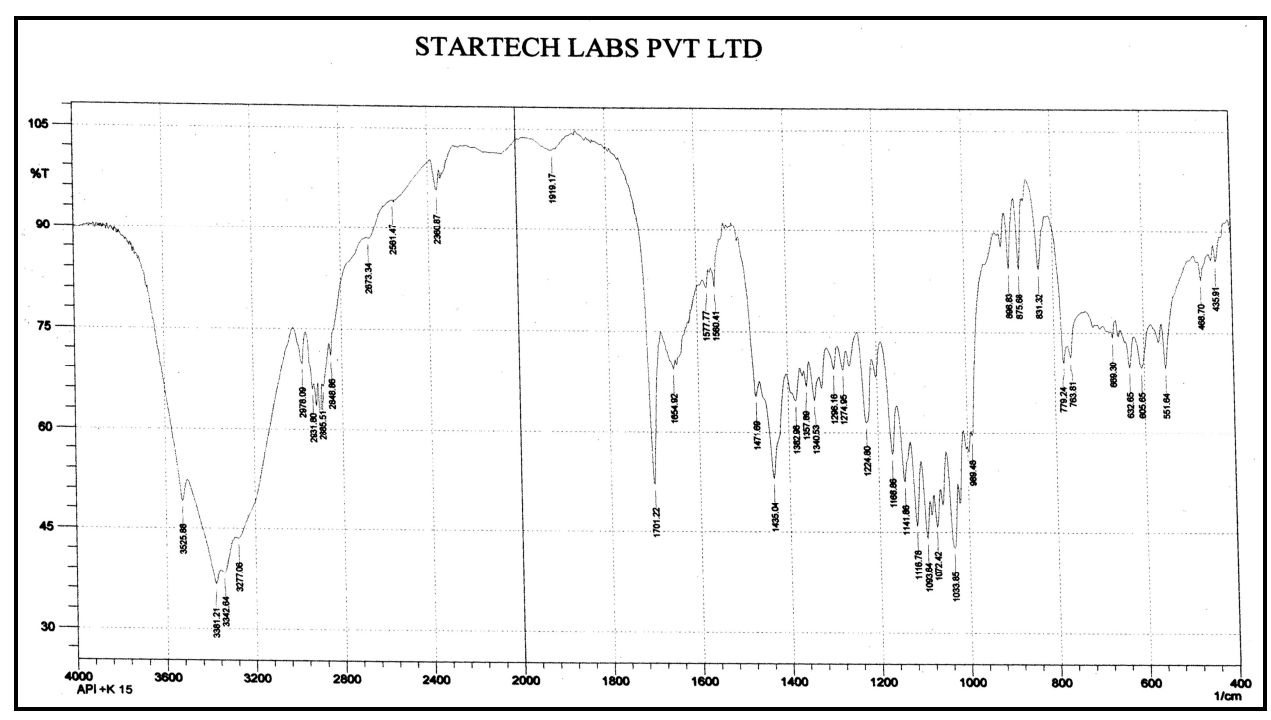

Fig. 3: FTIR spectrum of optimized formulation (F3); ( $n=1)$

\section{Pre-compression characterization}

\section{Drug excipient compatibility studies}

The drug excipient compatibility study was carried out by using DSC and FTIR. FTIR is one of the most powerful analytical techniques when it comes to the determination of the presence of various functional groups and DSC is a thermo analytical method in which the differentiation in the sum of heat required to raise the temperature of the sample and reference is precisely the same.

\section{Fourier transform infrared spectroscopy (FTIR)}

The spectral laboratory analysis of pure drug (LTD) and optimized formulation (F3) as shown in fig. 2 and fig. 3 correspondingly; principle peaks at similar wave-numbers and in an optimized formulation (F3) some different wave numbers observed.

However, these additional peaks were observed with physical mixtures, which could be due to the occurrence of polymers. The results advise that there is no reaction connecting the drug and polymers used in the current study.

\section{Differential scanning calorimetry (DSC)}

The thermal properties of the drug and the mixture of drugs and excipients are of important interest since this can help to assess the interaction among different components of the formulations (i.e., drug and other additives). Pure drug (LTD) and optimized formulation (F3) were subjected to DSC analysis.

The DSC curve of a pure drug (i.e. fig. 4) showed a sharp endothermic peak at $136.11^{\circ} \mathrm{C}$. The optimized formulation (F3) drug and Compritol 888 ATO showed a sharp endothermic peak at $135.10{ }^{\circ} \mathrm{C}$ (i.e. fig. 5). From the results, it was concluded that the drug was compatible with excipients used in formulations.

\section{Flow properties of the powder blend}

All prepared LTD powder blends are subjected to various parameters. The angle of repose ranges from $21.23 \pm 1.08$ (F2) to $31.40 \pm 1.05$ (F8); Carr's index ranges from 10.12 \pm 0.36 (F11) to15.36 \pm 0.47 (F4); Hausner's ratio values ranges from $1.06 \pm 1.01$ (F9) to $1.26 \pm 0.55$ (F7). From the above results, the powder blends (i.e. F1 to F12) showed well to excellent flow properties [46].

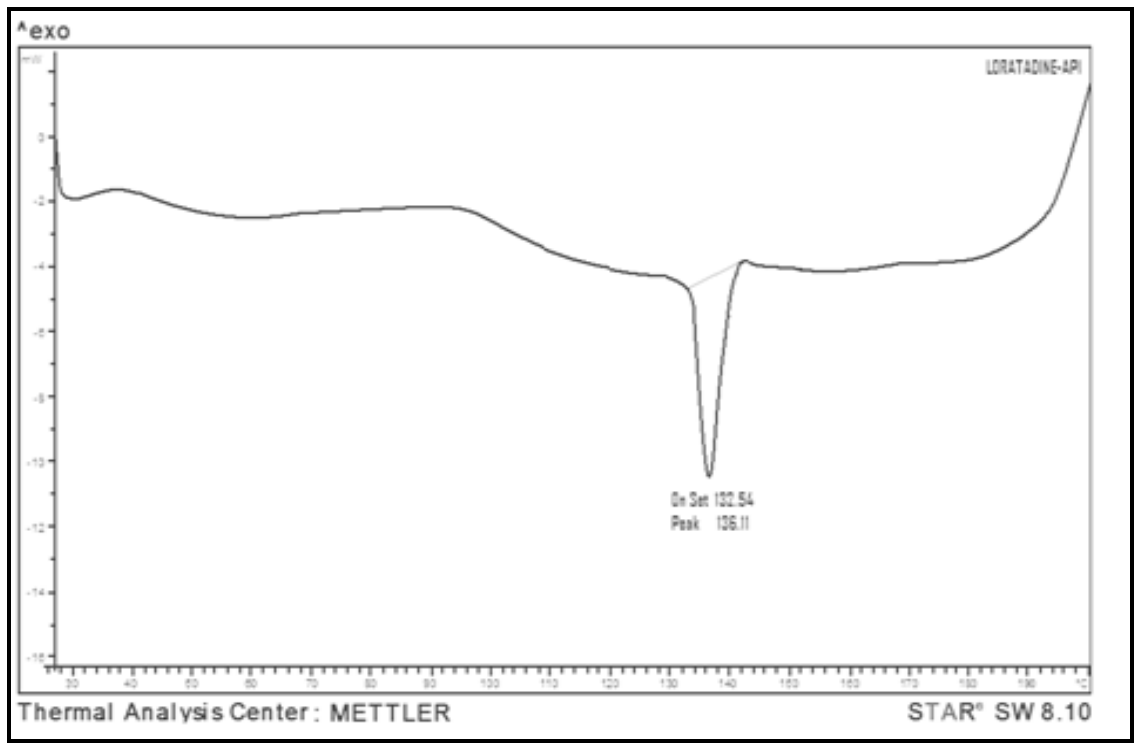

Fig. 4: DSC thermogram of pure drug (LTD); (n=1) 


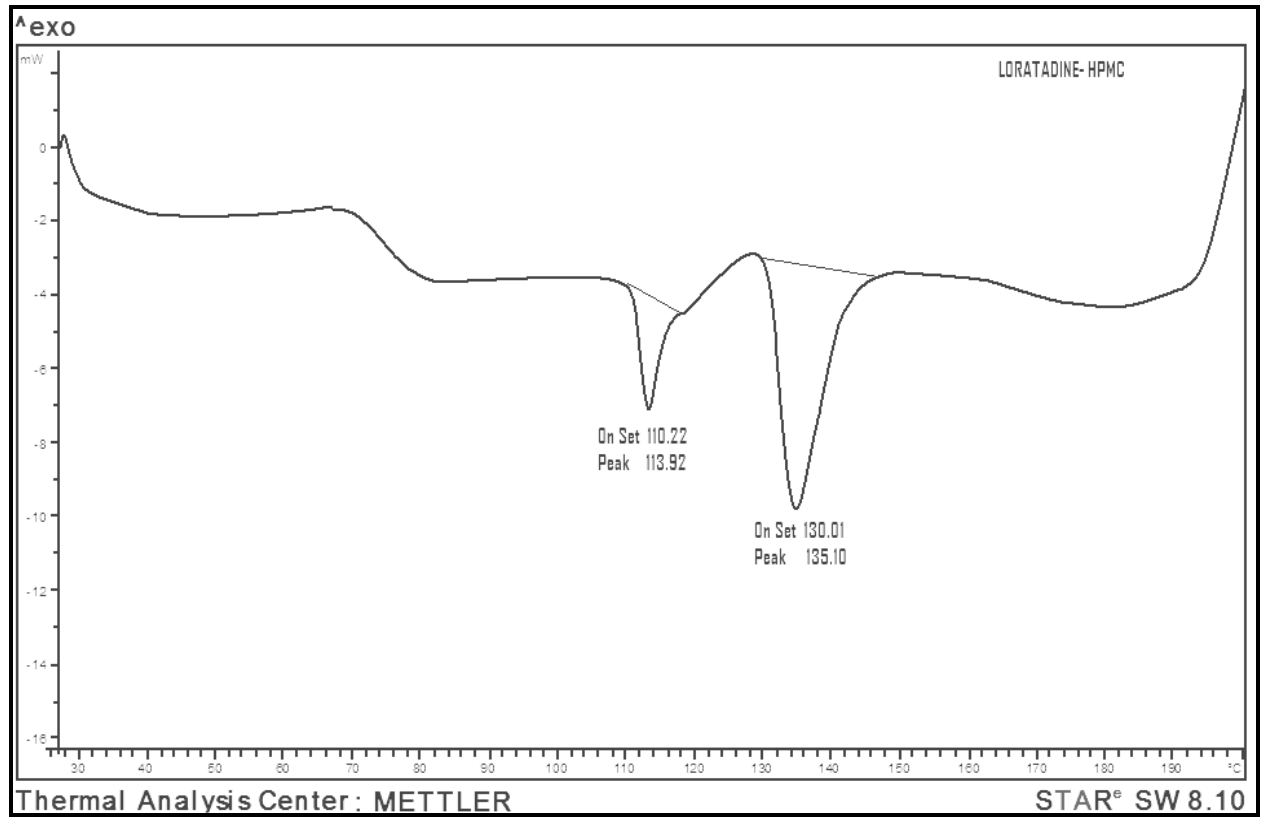

Fig. 5: DSC thermogram of optimized formulation (F3); $(n=1)$

Table 2: Pre-compression characterization of LTD floating matrix tablets

\begin{tabular}{|c|c|c|c|c|}
\hline Formulation code & Angle of repose ${ }^{\mathrm{a}}(\theta)$ & Carr's index ${ }^{\mathrm{a}}(\%)$ & Hausner's ratio $^{\mathrm{a}}$ & Flowability \\
\hline F1 & $26.51 \pm 1.26$ & $12.38 \pm 1.04$ & $1.12 \pm 0.44$ & Very good \\
\hline $\mathrm{F} 2$ & $21.23 \pm 1.08$ & $10.54 \pm 0.89$ & $1.10 \pm 0.38$ & Excellent \\
\hline F3 & $25.34 \pm 0.54$ & $14.79 \pm 0.63$ & $1.12 \pm 1.06$ & Very good \\
\hline F4 & $23.71 \pm 0.82$ & $15.36 \pm 0.47$ & $1.14 \pm 0.89$ & Very good \\
\hline F5 & $27.34 \pm 0.09$ & $13.79 \pm 1.02$ & $1.08 \pm 0.61$ & Good \\
\hline F6 & $23.23 \pm 0.06$ & $14.54 \pm 0.68$ & $1.17 \pm 0.74$ & Very good \\
\hline F7 & $21.34 \pm 0.84$ & $12.79 \pm 1.09$ & $1.26 \pm 0.55$ & Good \\
\hline F8 & $31.40 \pm 1.05$ & $12.08 \pm 0.53$ & $1.23 \pm 1.08$ & Good \\
\hline F9 & $28.52 \pm 1.02$ & $15.32 \pm 1.27$ & $1.06 \pm 1.01$ & Excellent \\
\hline F10 & $25.26 \pm 0.93$ & $14.36 \pm 0.84$ & $1.17 \pm 0.82$ & Very good \\
\hline F11 & $25.78 \pm 0.64$ & $10.12 \pm 0.36$ & $1.14 \pm 0.64$ & Very good \\
\hline F12 & $24.61 \pm 0.14$ & $12.09 \pm 0.52$ & $1.19 \pm 0.76$ & Very good \\
\hline
\end{tabular}

aEach value represents mean \pm SD $(n=3)$

\section{Post-compression characterization}

\section{Weight variation $(n=20)$}

The above-prepared formulations, 20 tablets from each batch (i.e. F1 to F12) were individually weighed in milligrams (mg) on electronic balance (Shimadzu, AUX 220, Japan) and results in ranges from $96.86 \pm 1.61 \mathrm{mg}(\mathrm{F} 10)$ to $100.08 \pm 0.01 \mathrm{mg}$ (F4).

\section{Thickness $(n=20)$}

Thickness is the only dimensional variable related to the compression process and is measured for all formulations (i.e. F1 to F12) by Vernier calipers and results range from $2.75 \pm 0.76 \mathrm{~mm}$ (F11) to $3.05 \pm 0.48 \mathrm{~mm}$ (F4).

\section{Friability $(\mathbf{n}=\mathbf{2 0})$}

Initially, weigh the tablets (i.e. total weight of the tablets is $\mathrm{W}_{1}$ ) and after 100 revolutions, de-dusted and reweighed (i.e. total weight of the tablets is $\mathrm{W}_{2}$ ) then worked at percentage weight loss and found the range from $0.12 \pm 0.65 \%$ (F10) to $0.49 \pm 0.07 \%$ (F4). Friability test of each one formulation (F1 to F12) was found satisfactory (i.e.<1\%) and viewing sufficient struggle to the mechanical shock and abrasion.

\section{Hardness $(n=6)$}

The hardness of the tablet was maintained for every batch, was instructed to play downwards on drug release because the effect of polymer concentration is the only area of interest and it was found between $4.27 \pm 1.08 \mathrm{~kg} / \mathrm{cm}^{2}$ (F5) to $6.09 \pm 1.10 \mathrm{~kg} / \mathrm{cm}^{2}$

\section{Drug content uniformity $(n=6)$}

The drug content was estimated by using UV visible spectrophotometer and the drug released from the entire prepared non-effervescent floating matrix tablets ranges from $96.16 \pm 1.15 \%$ (F8) to $99.81 \pm 1.54 \%$ (F7).

\section{In vitro buoyancy studies $(\mathrm{n}=3)$}

All prepared LTD floating matrix tablet formulations (F1 to F12) were evaluated for buoyancy; $0.1 \mathrm{~N} \mathrm{HCl}$ used as medium and lipid aids used to float the tablet without using any gas generating agents such as sodium bicarbonate, citric acid, and tartaric acid etc,. To develop the desired non-effervescent floating matrix tablets of LTD, it was needed to optimize the buoyant properties and release rates. The floating aids (Compritol 888 ATO and Precirol AT0 5), slow down the water diffusion and results in the buoyancy of dosage form over an encoded time. There was no FLT, (i.e. all prepared LTD non-effervescent floating matrix tablets buoyant was zero seconds) which means by floating aids the prepared tablets directly float on the surface of the medium (i.e. $0.1 \mathrm{~N} \mathrm{HCl}$ ) and the TFT of all prepared LTD formulations (i.e. F1 to F12) showed $\geq 12 \mathrm{~h}[47,48]$. The in vitro buoyancy was shown in fig. 6 and fig. 7. 
Table 3: Post-compression characterization of LTD floating matrix tablets

\begin{tabular}{|c|c|c|c|c|c|c|}
\hline $\begin{array}{l}\text { Formulation } \\
\text { code }\end{array}$ & $\begin{array}{l}\text { Weight variation }{ }^{\mathrm{a}} \\
\text { (mg) }\end{array}$ & $\begin{array}{l}\text { Thickness }^{\mathrm{a}} \\
\text { (mm) }\end{array}$ & $\begin{array}{l}\text { Friability }^{\mathrm{a}} \\
(\%)\end{array}$ & $\begin{array}{l}\text { Hardness }^{\mathrm{b}} \\
\left(\mathrm{Kg} / \mathrm{cm}^{2}\right)\end{array}$ & $\begin{array}{l}\text { Drug } \\
\text { content }{ }^{\mathrm{b}}(\%)\end{array}$ & $\begin{array}{l}\text { Matrix } \\
\text { integrity }\end{array}$ \\
\hline F1 & $98.88 \pm 1.01$ & $2.97 \pm 0.61$ & $0.22 \pm 1.25$ & $4.95 \pm 0.71$ & $97.25 \pm 0.87$ & Good \\
\hline $\mathrm{F} 2$ & $98.55 \pm 1.09$ & $2.95 \pm 0.52$ & $0.29 \pm 0.87$ & $5.07 \pm 0.85$ & $96.93 \pm 1.07$ & Very Good \\
\hline F3 & $99.06 \pm 1.03$ & $2.85 \pm 0.63$ & $0.41 \pm 0.35$ & $5.12 \pm 0.59$ & $99.86 \pm 1.54$ & Very Good \\
\hline F4 & $100.08 \pm 0.01$ & $3.05 \pm 0.48$ & $0.49 \pm 0.07$ & $6.01 \pm 1.63$ & $98.33 \pm 0.15$ & Excellent \\
\hline F5 & $99.55 \pm 1.25$ & $2.89 \pm 0.31$ & $0.21 \pm 1.15$ & $4.27 \pm 1.08$ & $97.90 \pm 1.09$ & Very Good \\
\hline F6 & $98.75 \pm 1.91$ & $2.95 \pm 0.74$ & $0.14 \pm 0.98$ & $5.37 \pm 0.58$ & $97.40 \pm 0.54$ & Excellent \\
\hline F7 & $98.88 \pm 1.02$ & $3.04 \pm 0.79$ & $0.21 \pm 0.56$ & $5.32 \pm 1.53$ & $99.81 \pm 1.54$ & Good \\
\hline F8 & $99.88 \pm 0.95$ & $2.85 \pm 0.93$ & $0.23 \pm 1.05$ & $4.96 \pm 1.43$ & $96.16 \pm 1.15$ & Very Good \\
\hline F9 & $98.01 \pm 1.06$ & $3.01 \pm 0.67$ & $015 \pm 1.54$ & $5.61 \pm 1.12$ & $98.31 \pm 0.76$ & Excellent \\
\hline F10 & $96.86 \pm 1.61$ & $2.79 \pm 0.31$ & $0.12 \pm 0.65$ & $4.35 \pm 1.56$ & $98.16 \pm 0.65$ & Good \\
\hline F11 & $98.98 \pm 0.75$ & $2.75 \pm 0.76$ & $0.24 \pm 1.34$ & $6.09 \pm 1.10$ & $98.83 \pm 0.20$ & Excellent \\
\hline F12 & $98.99 \pm 1.36$ & $2.96 \pm 0.27$ & $0.20 \pm 1.14$ & $4.38 \pm 1.12$ & $96.31 \pm 1.85$ & Excellent \\
\hline
\end{tabular}

aEach value represents mean $\pm S D(n=20)$; bach value represents mean $\pm S D(n=6)$

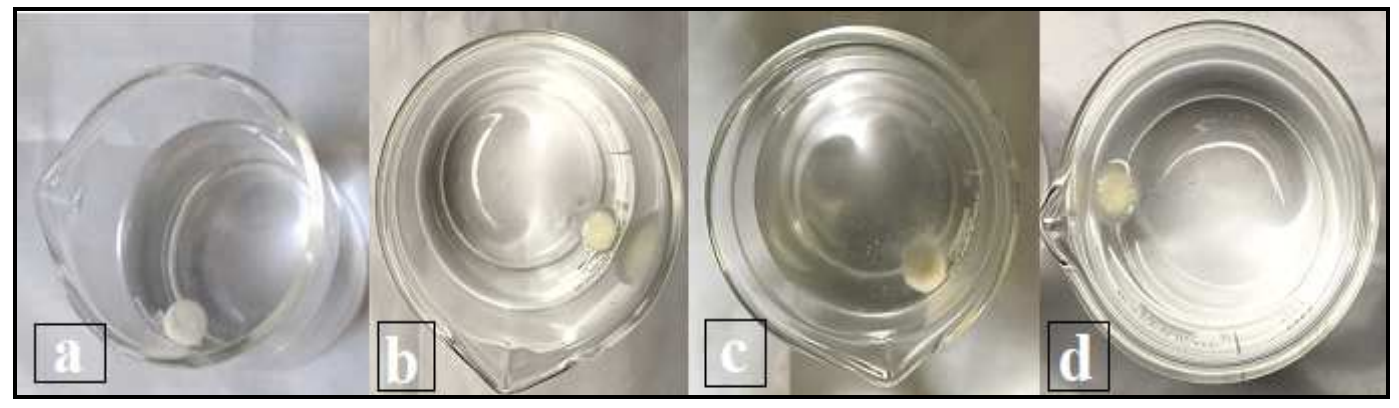

Fig. 6: Top views of in vitro buoyancy studies of optimized formulation (F3), a) at zero time b) at $3 \mathrm{~h} \mathrm{c}$ ) at $6 \mathrm{~h}$ d) at $12 \mathrm{~h}$; (n=3, mean \pm SD)

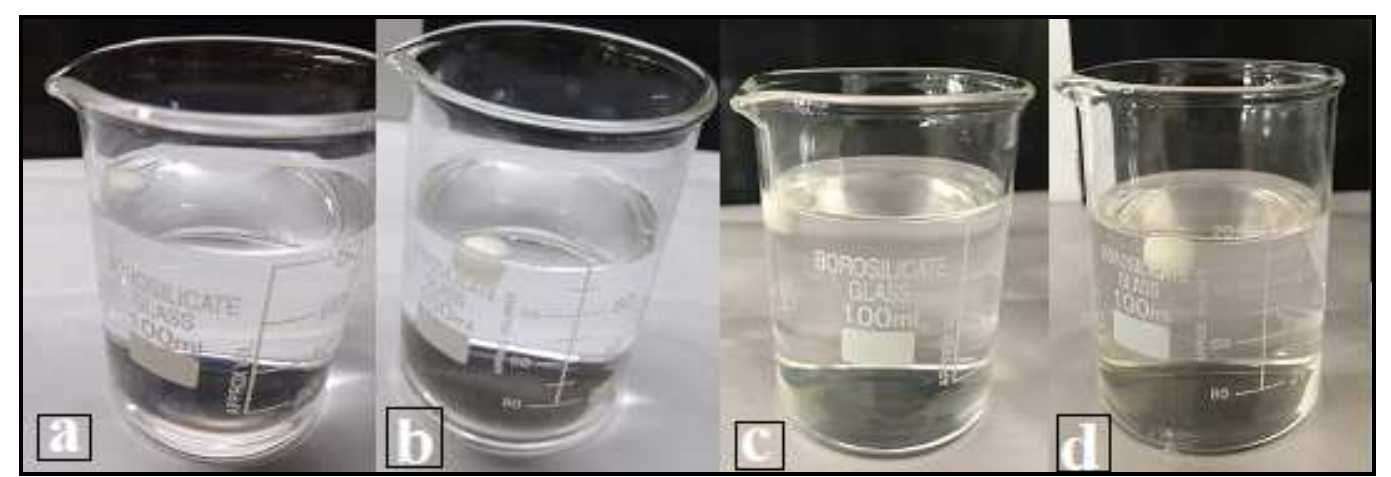

Fig. 7: Front view of in vitro buoyancy studies of optimized formulation (F3), a) at zero time b) at $3 \mathrm{~h}$ c) at $6 \mathrm{~h}$ d) at $12 \mathrm{~h}$; (n=3, mean \pm SD)

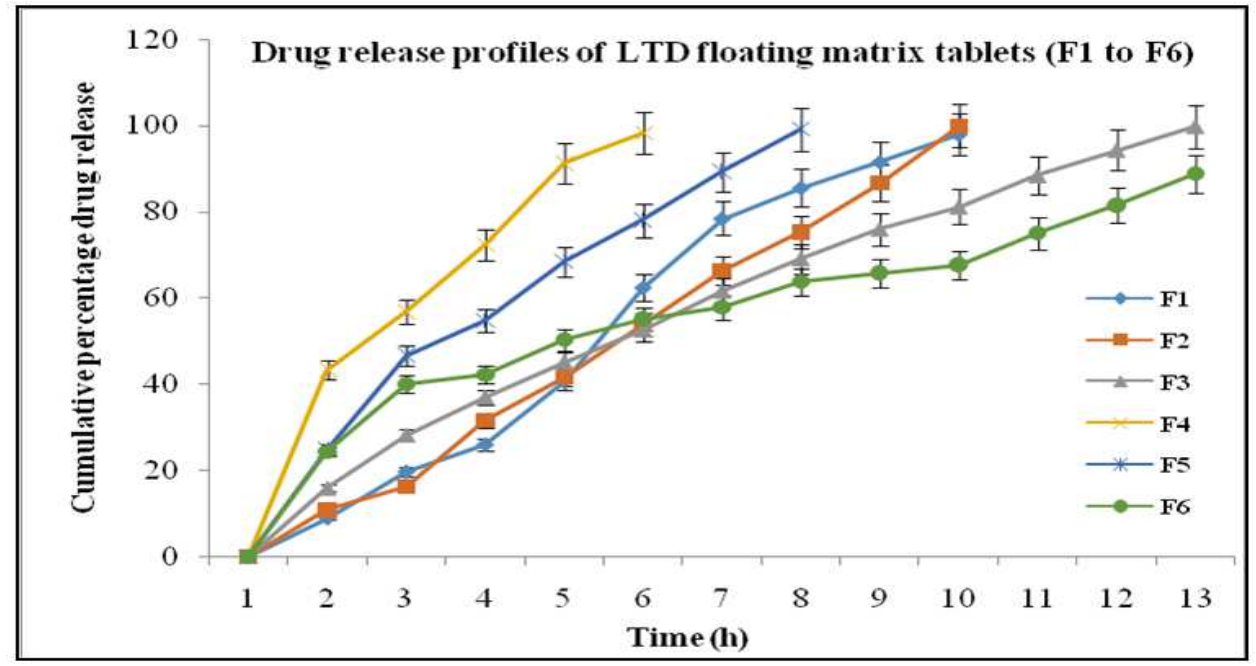

Fig. 8: Cumulative percentage drug release profiles of LTD prepared floating matrix tablets (F1 to F6); ( $=6$, mean \pm SD) 


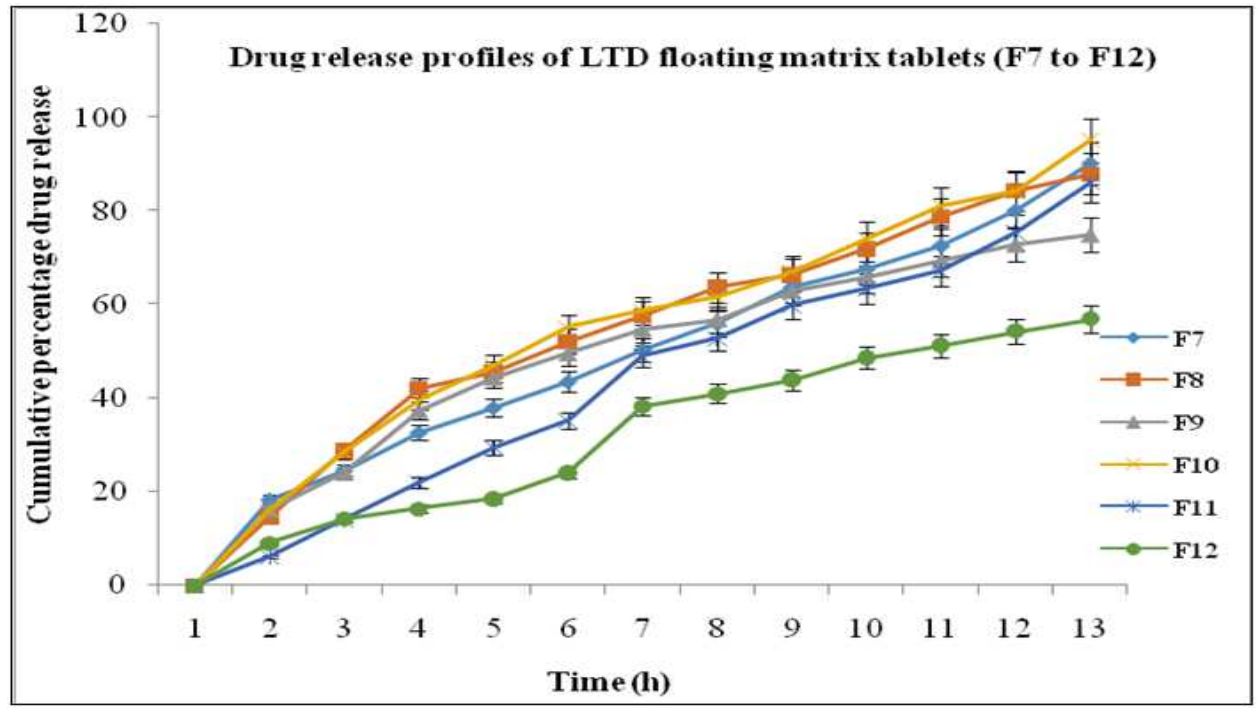

Fig. 9: Cumulative percentage drug release profiles of LTD prepared floating matrix tablets (F7 to F12); (n=6, mean \pm SD)

\section{In vitro dissolution $(\mathrm{n}=6)$}

The prepared LTD floating tablets were exposed to dissolution medium (i.e. $0.1 \mathrm{~N} \mathrm{HCl}$ ), the medium penetrates the free spaces, hydrating the polymer and lipid aid. Finally, it forms a gel-like consistency, from which the drug releases slowly for a prolonged time [49]. The cumulative percentage of drug releases was shown in fig. 8 and fig. 9. The most promising formulation was F3 because it cumulative percent of drug release was about $99.82 \pm 0.29 \%$ in $12 \mathrm{~h}$

\section{In vivo buoyancy studies $(\mathrm{n}=3)$}

The optimized formulation (F3) was prepared with the same compression force as $\mathrm{BaSO}_{4}$. All the physicochemical properties were within the pharmacopoeial limits [50]. In vivo, radiographic studies were conducted on 3 healthy male human volunteers with a glass of water and a standard diet was provided to find out the GRT of the tablets. X-ray pictures were taken at different time intervals such as 1,3 and $6 \mathrm{~h}$.

The X-ray image shows that tablets remain in the stomach for about $6 \mathrm{~h}$ and which indicate the good floating property (shown in fig. 10). These studies revealed that the mean GRT was found to be $6 \pm 0.5 \mathrm{~h}$.

\section{Mechanism of drug release kinetics}

Various models were tested for explaining the kinetics of drug release. To analyze the mechanism of the drug release, the dissolution data were fitted into zero-order, First order, and Higuchi and Korsmeyer Peppas models. In all formulations (F1 to F12), the diffusion exponent value was $>5$. The correlation coefficient $\left(\mathrm{R}^{2}\right)$ and diffusion exponent (n) of release data of all prepared LTD non-effervescent floating tablets (i.e. F1 to F12 formulations) were calculated. The optimized formulation F3 followed the Peppas model $\left(\mathrm{R}^{2}=0.996\right)$ with the nonFickian mechanism and it was shown in table 4.

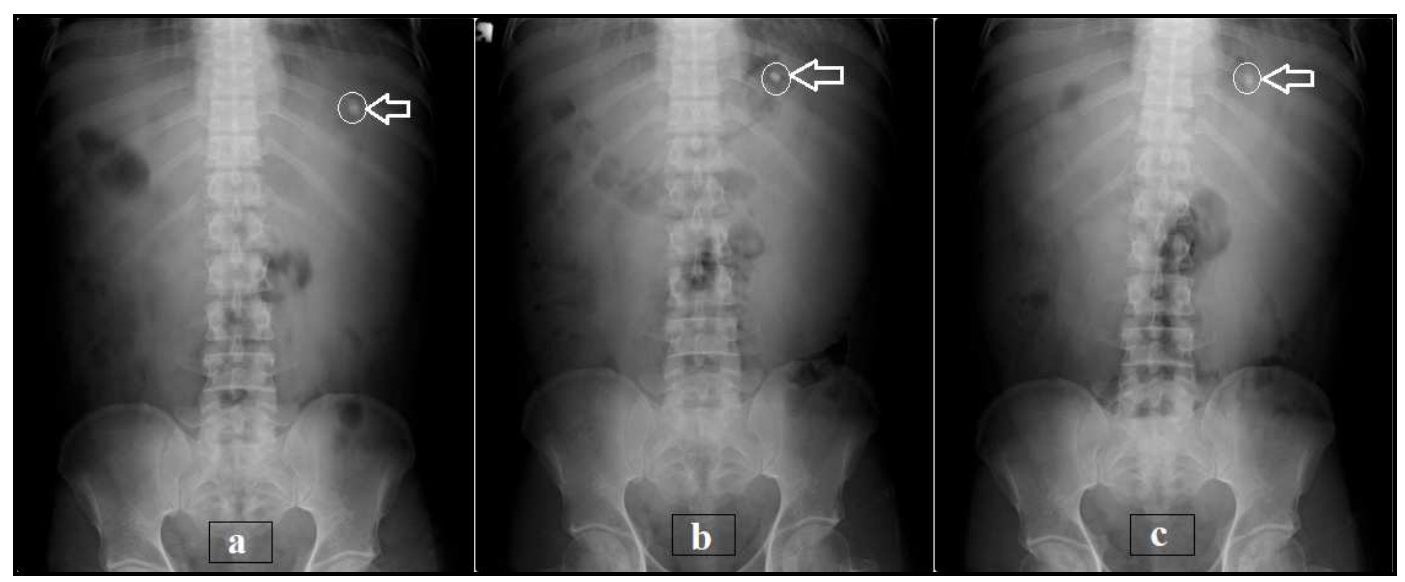

Fig. 10: X-ray images of optimized formulation (F3); a) at $30 \mathrm{~min}$; b) at $3 \mathrm{~h}$; c) at $6 \mathrm{~h}$ (tablet position was indicated with the circle and arrow mark); ( $=3$, mean $\pm S D)$

Table 4: Compilation of the results from all the mathematical models applied to the optimized formulation (F3)

\begin{tabular}{llcccc}
\hline Formulation code & Zero-order & First-order & Higuchi & Hixon crowell & Korsmeyer peppas \\
\cline { 2 - 5 } & \multicolumn{3}{c}{$\mathbf{R}^{2}$} & $\mathbf{R}^{2}$ & 0.862 \\
\hline${ }^{*}$ F3 & 0.978 & 0.869 & 0.914 & 0.996 \\
\hline
\end{tabular}

${ }^{*}$ Each value represents mean \pm SD $(n=6)$ 


\section{CONCLUSION}

The LTD non-effervescent floating tablets were developed by using HPMC K15, HPMC K 100 as release retardants and Compritol 888 ATO, Precirol ATO 5 were used as floating aids. From the above DSC and FTIR results, there was no drug and excipient interaction found in the formulations. All the formulations showed good physicochemical characteristics and F3 formulation was optimized based on all parameters. The radio-graphical studies revealed a mean GRT of $6 \pm 0.5 \mathrm{~h}$. From the above results, it was concluded that the formulations retained in the stomach for a longer period and extended the drug release. Hence, this dosage form helped to improve the absorption of LTD.

\section{AUTHORS CONTRIBUTIONS}

All authors have contributed equally

\section{CONFLICT OF INTERESTS}

The authors declare that there is no conflict of interest

\section{REFERENCES}

1. Shweta P. Formulation and evaluation of garlic powder loaded floating matrix tablet. Int J Pharm Pharma Sci 2019;11:17-21.

2. Shah R, Patel S, Patel H, Pandey S, Shah S, Shah D. Formulation development of carvedilol compression coated tablet. Int J Pharm Pharma Sci 2013;18:906-15.

3. Nachaegari SK, Bansal AK. Co-processed excipients for solid dosage forms. Pharm Technol 2004;28:52-65.

4. York P. Solid-state properties of powders in the formulation and processing of solid dosage forms. Int J Pharma 1983;14:1-28.

5. Badawy SI, Hussain MA. Microenvironmental $\mathrm{pH}$ modulation in solid dosage forms. J Pharm Sci 2007;96:948-59.

6. Davies P. Oral solid dosage forms. Mark G. editor. In: Pharmaceutical pre-formulation and formulation, $2^{\text {nd }}$ ed. New York; CRC Press; 2015. p. 367-430.

7. Jadi RK, Chinnala KM. A comprehensive review on gastroretentive drug delivery systems. Ind Am J Pharm Sci 2016;3:115-28.

8. Dixit N, Maurya SD, Sagar BP. Sustained release drug delivery system. Ind J Res Pharm Biotech 2013;1:305-10.

9. Prinderre P, Sauzet C, Fuxen C. Advances in gastro retentive drug-delivery systems. Expert Opin Drug Delivery 2011;8:1189-203.

10. Mandal UK, Chatterjee B, Senjoti FG. Gastro retentive drug delivery systems and their in vivo success: a recent update. Asian J Pharma Sci 2016;11:575-84.

11. Nokhodchi A, Raja S, Patel P, Asare Addo K. The role of oral controlled release matrix tablets in drug delivery systems. BioImpacts 2012;2:175-87.

12. Dhiman S, Singh TG, Rehni AK, Sood S, Arora S. Gastroretentive: a controlled release drug delivery system. Asian J Pharm Clin Res 2011;4 Suppl 1:5-13.

13. Harshad P, Omkar L. Formulation and evaluation of bilayer tablet containing diclofenac sodium as a sustained release and aloe vera gel powder as immediate release. Int J Curr Pharm Res 2019;11:70-8.

14. Shivshankar RM. Advances of hydrazone linkers in polymeric drug delivery. J Crit Rev 2019;6:1-4.

15. Tanner T, Marks R. Delivering drugs by the transdermal route: review and comment. Skin Res Technol 2008;14:249-60.

16. Willingham E, Agras K, Vilela M, Baskin LS. Loratadine exerts estrogen-like effects and disrupts penile development in the mouse. J Urol 2006;175:723-6.

17. Simons FE. Advances in H1-antihistamines. New Eng J Med 2004;351:2203-17.

18. Baena Cagnani CE. Safety and tolerability of treatments for allergic rhinitis in children. Drug Safety 2004;27:883-98.

19. Kumria R, Nair AB, Al-Dhubiab BE. Loratidine buccal films for allergic rhinitis: development and evaluation. Drug Dev Ind Pharm 2014;40:625-31.

20. Bernstein IL, Bernstein DI. The efficacy and safety of loratadine in the management of chronic idiopathic urticaria. J Allergy Clin Imm 1988;81:211.
21. Kirshner JJ, Heckler CE, Tiffany S, Reichel C, McAuliffe C, Morrow GR. A phase II study of loratidine (L) to prevent pegfilgrastim-induced pain (PIP). J Clin Oncol 2011;29 Suppl 15:e19704.

22. Siraj S, Khurshid M, Nazim S. Various perspectives of gastroretentive drug delivery system: a review. Am J Adv Drug Delivery 2013;1:443-51.

23. Mishra S, Pathak K. Formulation and evaluation of oil entrapped gastroretentive floating gel beads of loratadine. Act Pharma 2008;58:187-97.

24. Sharma AR, Khan A. Gastroretentive drug delivery system: an approach to enhance gastric retention for prolonged drug release. Int J Pharma Sci Res 2014;5:1095-106.

25. Radhakrishnan P, Singh SK, Verma PR. Pharmaceutical formulations to increase gastric residence time: concepts and strategies. Drug Delivery Lett 2017;7:190-200.

26. Jadi RK, Tatikonda A, Reedy PR, Venisetty RK. Design and characterization of pregabalin swellable core osmotic pumps. Int J Pharm Res Allied Sci 2016;5:8-15.

27. Togaru V, Venisetty RK, Bakshi V, Jadi RK. Formulation development and in vitro evaluation of propranolol hydrochloride extended-release matrix tablets. Emergent Life Sci Res 2017;3:38-47.

28. Roy H, Parida KR, Nandi S, Panda SK, Mohapatra DK. Design of fast dissolving amlodipine besylate tablet formulations. Asian J Pharm 2014;6:51-9.

29. El Ragehy NA, Badawey AM, Khateeb SE. Stability indicating methods for the determination of loratadine in the presence of its degradation product. J Pharm Biomed Anal 2002;28:104153.

30. Hilbert I, Radwanski E, Weglein R, Luc V, Perentesis G, Symchowicz S, et al. Pharmacokinetics and dose proportionality of loratadine. J Clin Pharm 1987;27:694-8.

31. Yeleken G, Kotłowska H, Sznitowska M, Golenia E, Ustenova G. Development of direct compressed loratadine minitablets. J Pharma Sci Res 2017;9:401-6.

32. Kumar AD, Rani JM, Sudhakarbabu AM, Rao VP. Formulation optimization and evaluation of loratadine gastroretentive tablets. Int J Bio Pharma Res 2013;4:1190-5.

33. Bomma R, Naidu RS, Yamsani M, Veerabrahma K. Development and evaluation of gastroretentive norfloxacin floating tablets. Acta Pharm 2009;59:211-21.

34. Guguloth M, Bomma R, Veerabrahma K. Development of sustained-release floating drug delivery. J Pharm Sci Technol 2011;65:198-206.

35. Dudhipala N, Narala A, Janga KY, Bomma R. Amoxycillin trihydrate floating-bioadhesive drug delivery system for eradication of helicobacter pylori: preparation, in vitro and ex vivo evaluation. J Bioequivalence Bioavailability 2016;8:118-24.

36. Prasad RR, Kumar JR, Vasudha BA, Chettupalli AK. Formulation development and evaluation of allopurinol solid dispersions by solvent evaporation technique. Int J Appl Pharm 2018;10:168-71.

37. Pandala S, Bakshi V, Jadi RK. Formulation development and in vitro characterization of zolmitriptan controlled release drug delivery systems. INNOSC Theranostics Pharmacol Sci 2019;2:6-11.

38. Reddy RA, Ramesh B, Kishan V. Drug excipient interaction during formulation development, in vitro and in vivo evaluation of gastroretentive drug delivery system for nizatidine. Int J Pharm Sci Nanotech 2013;6:2281-93.

39. Bomma R, Veerabrahma K. Statistical optimization of floatingbioadhesive drug delivery system for risedronate sodium: in vitro, ex vivo and in vivo evaluation. Int J Drug Delivery 2014;6:36-49.

40. Parmar K, Patel J, Sheth N. Self nano-emulsifying drug delivery system for embelin: design, characterization and in vitro studies. Asian J Pharma Sci 2015;10:396-404.

41. Bera H, Boddupalli S, Nandikonda S, Kumar S, Nayak AK. Alginate gel-coated oil-entrapped alginate-tamarind gummagnesium stearate buoyant beads of risperidone. Int J Biol Macromol 2015;78:102-11.

42. Van Lenthe E, Ehlers A, Baerends EJ. Geometry optimizations in the zero-order regular approximation for relativistic effects. J Chem Phys 1999;110:8943-53. 
43. Dash S, Murthy PN, Nath L, Chowdhury P. Kinetic modeling on drug release from controlled drug delivery systems. Acta Pol Pharm 2010;67:217-3.

44. Singhvi G, Singh M. In vitro drug release characterization models. Int J Pharm Stud Res 2011;2:77-84.

45. Costa P, Lobo JM. Modeling and comparison of dissolution profiles. Eur J Pharma Sci 2001;13:123-33.

46. Lopes CM, Bettencourt C, Rossi A, Buttini F, Barata P. Overview on gastroretentive drug delivery systems for improving drug bioavailability. Int J Pharm 2016;510:144-58.

47. Bera H, Boddupalli S, Nandikonda S, Kumar S, Nayak AK. Alginate gel-coated oil-entrapped alginate-tamarind gum- magnesium stearate buoyant beads of risperidone. Int I Biol Macromol 2015;78:102-11

48. Satishbabu BK, Sandeep VR, Ravi RB, Shrutinag R. Formulation and evaluation of floating drug delivery system of famotidine. Ind J Pharm Sci 2010;72:738-44.

49. Adel S, ElKasabgy NA. Design of innovated lipid-based floating beads loaded with an antispasmodic drug: in vitro and in vivo evaluation. J Liposome Res 2014;24:136-49.

50. Jadi RK, Bomma R, Sellappan V. Development of a new single unit dosage form of propranolol $\mathrm{HCl}$ extended-release noneffervescent floating matrix tablets: in vitro and in vivo evaluation. J Appl Pharm Sci 2016;6:112-8. 